\title{
Electrochemical Behavior of a New Precursor for the Design of Poly[Ni(salen)]-Based Modified Electrodes
}

\author{
Miguel Vilas-Boas, ${ }^{\dagger, l}$ I sabel C. Santos, ${ }^{\dagger}$ Mark J. Henderson, ${ }^{\ddagger}$ Cristina Freire, ${ }^{*}{ }^{\dagger}$ \\ A. Robert Hillman, $*, \neq$ and Eric Vieil $\$$ \\ REQUIMTE, Departamento de Química, Faculdade de Ciências, Universidade do Porto, \\ 4169-007 Porto, Portugal, Department of Chemistry, University of Leicester, \\ Leicester LE1 7RH, United Kingdom, Laboratoi re d'E lectrochimie Moléculaire, Départment de \\ Recherche Fondamentale sur la Matière Condensée, CEA, 38054 Grenoble Cedex 9, France, \\ and $\mathrm{Cl} \mathrm{MO}$ / Departamento de Ciências-Básicas, Escola Superior Agrária de Bragança, \\ 5301-855 Bragança, Portugal
}

Received March 27, 2003. In Final Form: J uly 3, 2003

\begin{abstract}
Wedescribethe potentiodynami c preparation and subsequent characterization of poly[Ni(3-MeOsaltMe)] films (surface concentration, $3<\Gamma / \mathrm{nmol} \mathrm{cm}^{-2}<350$ ) in acetonitrile media. Coulometric and gravimetric (electrochemical quartz crystal microbalance, EQCM) data allow oneto monitor the deposition process and show that theresultant films are physically and chemically stable. Combined E QCM/probebeam deflection measurements were used to quantify theindividual contributions (fluxes and population changes) of anions, cations, and solvent to the overall redox switching process. The first redox cycle for a film "rested" in the reduced state results in accumulation of anion (charge) and solvent in the film. The subsequent steadystate response is domi nated by a combi nation of ani on and sol vent transfers; this takes place in twostages, thesecond of which involves significantly moresolvent entry, toan extent dependent upon time scale. After a sequence of redox cycles, the initial thermodynamically "irreversible" behavior is restored by "resting" the film. Solvation effects are critical determinants of film redox chemistry and dynamics: in addition to controlling the feasibility and stability of deposition, they control film ion transport rate.
\end{abstract}

\section{Introduction}

Polymers prepared by oxidative polymerization of $\mathrm{Ni}$ (salen)-typemonomers in low coordinating solvents are novel materials, ${ }^{1-9}$ since they contain discrete redox sites ( $\mathrm{Ni}$ centers) and delocalized redox units (the extended conjugated system in the polymerized salen-type ligand). Wehave done a systematicstudy on films prepared using nickel monomers derived from salicylaldehyde and different substituted ethylenediamines. ${ }^{5-10}$ The spectroelectrochemical characterization has shown that these films

* To whom correspondence should be addressed. Cristina Freire: fax, ++351-226082959; e-mail, acfreire@fc.up.pt. A. Robert Hillman: fax, ++44-116-2525227; e-mail, arh7@e.ac.uk.

† REQUIMTE, Departamento de Química, Faculdade de Ciências, Universidade do Porto.

‡ Department of Chemistry, University of Leicester.

$\S$ Laboratoire d'Electrochimie Moléculaire, Départment de Recherche F ondamentale sur la Matière Condensée, CEA.

" CIMO/Departamento de Ciências-Básicas, Escola Superior Agrária de Braganca.

(1) Audebert, P.; Hapiot, P.; Capdevielle, P.; Maumy, M. J . Electroanal. Chem. 1992, 338, 269.

(2) Bedioui, F.; Labbe, E.; Gutierrezgranados, S.; Devynck, J . J. Electroanal. Chem. 1991, 301, 267.

(3) Goldsby, K. A.; Blaho, J. K.; Hoferkamp, L. A. Polyhedron 1989, 8, 113.

(4) Dahm, C. E.; Peters, D. G.; Simonet, J J J . Electroanal. Chem 1996, 410, 163.

(5) Vilas-Boas, M.; Henderson, M.J .; Freire, C.; Hillman, A. R.; Vieil,

E. Chem.-Eur. J . 2000, 6, 1160.

(6) Vilas-Boas, M.; Freire, C.; Castro, B.; Christensen, P. A.; Hillman, A. R. Inorg. Chem. 1997, 36, 4919.

(7) Vilas-Boas, M.; Freire, C.; deCastro, B.; Hillman, A. R. J . Phys. Chem. B 1998, 102, 8533.

(8) Vilas-Boas, M.; Freire, C.; Castro, B.; Christensen, P. A.; Hillman, A. R. Chem.-Eur. J . 2001, 7, 139.

(9) Pereira, E. M.; Vilas-Boas, M.; Freire, C.; Hillman, A. R. J . Electroanal. Chem. 2002, 538-539, 47.

(10) Vilas-Boas, M. El léctrodos M odificados por Polimerizaçãol n Situ de Complexos de Níquel(II) com Bases de Schiff. Ph.D. Thesis, Universidade do Porto, Porto, Portugal, 2000. exhibit similar $E_{1 / 2}$ values and analogous UV-vis and IR spectra in the reduced and oxi dized states but can exhi bit quitedifferent electrochemical stability, which was shown to be determined mainly by the bulkiness of the imine bridge substituents. Within the group of monomers used ([Ni(salR)], R = different imine bridges), that with the ethylenic bridge substituted with four methyl groups (denoted as [Ni(saltMe)]) has allowed the preparation of polymericfilms with the highest stability. This prompted us to characterize poly[Ni(saltMe)] using a plethora of techniques: cyclic vol tammetry and chronoamperometry to study film redox activity and charge transport, ${ }^{7} \mathrm{UV}-$ vis, FTIR, electron paramagnetic resonance (EPR), and ellipsometry to explore the polymer configuration and electronic structure, ${ }^{8,11}$ electrochemical quartz crystal microbalance (EQCM) and probe beam deflection (PBD) to characterize ion and solvent transfer processes driven by redox switching, ${ }^{5}$ and rotating disk electrode (RDE) voltammetry in the presence of ferrocene-based redox couples to evaluatefilm membrane/mediator properties. ${ }^{9}$ Thesestudies have provided insights intothesources and sinks (within the film) of the mobile species, along with their transport rates, that control the rate at which one can drive film redox processes.

We choose to pursue the study on poly[Ni(salen)] films by introducing substituents in theal dehyde moiety of the parent monomer and determine their influence upon the overall properties of the resulting conducting films. Our strategy commences by introducing substituents into the [Ni(saltM e)] motif (which has led tothemost stablefilms), and we have started with methoxy substitution in the 3 position of the aldehyde; the resulting monomer, $\mathrm{N}, \mathrm{N}^{\prime}-$ 2,3-dimethyl butane-2,3-dyil-bis(3-methoxysalicylideneiminate) nickel(II), denoted as [Ni(3-MeOsaltMe)], is

(11) Abel, J .; Vilas-Boas, M.; Freire, C.; Hillman, A. R.; Christensen, P. A.; Hamnett, A. In preparation. 


\section{Chart 1. Schematic Representation of the Nickel Monomer [Ni(3-MeOsaltMe)]}

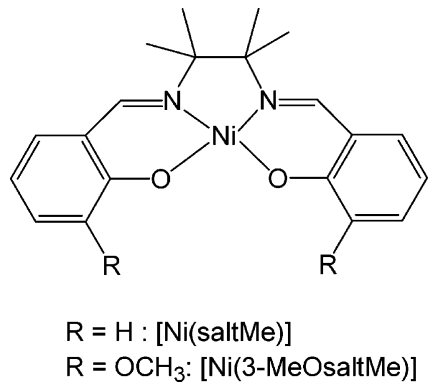

represented in Chart 1 . With this substitution, we have been able to synthesize monomers that exhibit solution recognition properties for cations (alkaline earths and lanthanides), ${ }^{12}$ and through their polymerization welook forward to extending this property to polymeric films.

Herein we describe the potentiodynamic preparation and subsequent electrochemical and physical characterization of poly[Ni(3-MeOsaltMe)] films (surface concentration, $3<\Gamma / \mathrm{nmol} \mathrm{cm}-2<350$ ) in acetonitrile media; spectroscopic and optical properties will be published elsewhere. Coulometric and gravimetric (EQCM) data allow oneto monitor the deposition process and show that the resultant films are physically and chemically stable. Combined EQCM/PBD measurements were used to quantify the individual contributions (fluxes and population changes) of anions, cations, and solvent totheoverall redox switching process.

\section{Experimental Section}

Chemicals. Solvents werereagent gradeand used as received for syntheses. For electrochemical purposes, acetonitrile, $\mathrm{CH}_{3} \mathrm{CN}$ (Fisons, HPLC grade), was refluxed twice over $\mathrm{CaH}_{2}$ and distilled under an argon atmospherewhile DMF and $\left(\mathrm{CH}_{3}\right)_{2-}$ SO (Merck, proanalysis) wereused without further purification. Tetraethylammonium perchlorate (TEAP; Fluka, Puriss) was used as received and kept in an oven at $60^{\circ} \mathrm{C}$. The acetonitrileTEAP solutions used in EQCM - PBD experiments were filtered with a $0.1 \mu \mathrm{m}$ poly(tetrafluoroethylene) (PTFE) membrane (Whatman) to remove microscopic solid particles from ambient dust that could scatter the laser beam. The ligand $\left[\mathrm{H}_{2}(3-\mathrm{Me}\right.$ OsaltMe)], N,N'-2,3-dimethylbutane-2,3-dyil-bis(3-methoxysalicylideneimine), and the corresponding $\mathrm{Ni}(\mathrm{II})$ complex, [Ni(3MeOsaltMe)], were prepared by standard methods ${ }^{13}$ and recrystallized from $\mathrm{CH}_{3} \mathrm{CN}$.

Electrochemistry. The electrochemical apparatus used in cyclic voltammetry and in double potential step chronoamperometry is described elsewhere, ${ }^{7}$ with a Pt disk (area $=0.0314$ $\mathrm{cm}^{2}$ ) as the working electrode (WE), a Pt gauze as the counter el ectrode, and a saturated calomel el ectrode (SCE) as reference electrode; the SCE was inserted into a glass tube filled with electrolytesolution and separated from theWE compartment by a glass membrane. All solutions were deaerated and delivered to the electrochemical cell by a stream of argon. The electrochemical cell used in EQCM-PBD studies was as previously described. ${ }^{14,15}$ Theworking el ectrodewas a $10 \mathrm{M} \mathrm{Hz}$ quartz crystal coated with a platinum fil m (electrochemical area, $0.25 \mathrm{~cm}^{2}$ ) and mounted via silicone sealant on the end of a glass tube with the sameexternal diameter $(13 \mathrm{~mm})$ as the quartz crystal. ${ }^{16} \mathrm{~A}$ Pt foil was used as the counter electrode, and a SCE as the reference electrode.

(12) Sousa, C. Reconhecimento de metais representativos e de lantanídeos por complexos de metais de transição com Bases de Schiff funcionalizadas. Ph.D. Thesis, U niversidade do Porto, Porto, Portugal 2001.

(13) Holm, R. H.; Everett, G. W.; Chakravorty, A. Prog. Inorg. Chem. 1966, 7, 183.

(14) Henderson, M. J .; Hillman, A. R.; Vieil, E.; Lopez, C. J. Electroanal. Chem. 1998, 458, 241.

(15) Henderson, M. J .; Hillman, A. R.; Vieil, E. J . Phys. Chem. B $1999,103,8899$
EQCM-PBD. Crystal impedance measurements were performed with a Hewlett-Packard HP8512A network analyzer in reflectancemode, as described previously. ${ }^{16}$ Theadmittancedata acquisition was computer controlled by a HP BASIC program running on thenetwork analyzer built-in computer. Thetechnical description for the deflection and gravimetric apparatus used in the simultaneous el ectrochemical-gravimetric-deflection studies can be found el sewhere. $5,14,15$ The piezoel ectric area of the Pt working electrode was $0.22 \mathrm{~cm}^{2}$.

Scanning Electron Microscopy. A scanning electron microscope (J EOL J 5M 35C) was used to provide morphological characterization of the polymer films deposited on indium-tin oxideel ectrodes (ITO)-coated conducting glass (Balzers). F or this purpose, the polymer deposition was achieved either by potentiodynamic conditions similar to those described below for the electrochemical characterization or by potentiodynamic conditions but with thecell immersed in an ultrasound bath. After the film deposition, the ITO el ectrode was fractured and coated with a carbon layer to allow dissipation of the surface charge accumulated during exposure to the electron beam.

Procedures. Film deposition invol ved cycling the potential of the working el ectrode between 0.0 and 1.1 or $1.3 \mathrm{~V}$ (see bel ow), in a solution containing $0.1 \mathrm{~mol} \mathrm{dm}^{-3}$ TEAP and $1 \mathrm{mmol} \mathrm{dm}^{-3}$ of [ $\mathrm{H}_{2}$ (3-M eOsaltMe)] or [Ni(3-MeOsaltMe)]. $\mathrm{CH}_{3} \mathrm{CN}, \mathrm{DMF}$, and $\left(\mathrm{CH}_{3}\right)_{2} \mathrm{SO}$ were used as solvents for electrochemical characterization. The typical scan rate (v) used for deposition was $0.1 \mathrm{~V}$ $\mathrm{s}^{-1}$; higher scan rates were required for the ligand study (see figure legends).

After el ectrodeposition, themodified el ectrodewas rinsed with $\mathrm{CH}_{3} \mathrm{CN}$ and then transferred to $0.1 \mathrm{~mol} \mathrm{dm}^{-3} \mathrm{TEAP} /$ solvent solutions. For cyclic voltammetric experiments, the film was cycled between 0.0 and $1.3 \mathrm{~V}$ at scan rates in the range $0.005-$ $2.0 \mathrm{~V} \mathrm{~s}^{-1}$. For chronoamperometric experiments, the polymer was first scanned at $0.1 \mathrm{~V} \mathrm{~s}^{-1}$ until a reproduci blevoltammogram was observed, and then two different potential step programs were applied: (i) from 0.0 to $0.55 \mathrm{~V}$ and then, after $30 \mathrm{~s}$, back to $0.0 \mathrm{~V}$; and (ii) from 0.0 to $1.15 \mathrm{~V}$ and then, after $30 \mathrm{~s}$, back to $0.0 \mathrm{~V}$. In theE QCM - PBD experiments, thefilm was cycled until reproducible voltammetric responses were observed (usually 5-10 cycles) and only then transferred to the E QCM-PBD cell. This procedure avoids problems associated with trapping of monomer within the film. For the latter studies, the potential limits in monomer-free experiments were varied between 0.0 and $1.3 \mathrm{~V}$, and the scan rate was $0.1 \mathrm{~V} \mathrm{~s}^{-1}$.

The polymer surface concentration of each film, expressed in terms of moles of monomer per unit area $\left(\Gamma / \mathrm{mol} \mathrm{cm}^{-2}\right)$, was determined by coulometric assay in monomer-free solution. As demonstrated below, surface concentration was calculated on the basis of two positive charges being delocalized over three monomer units in the oxidized film. Coulometric assays were conducted using a scan rate of $0.01 \mathrm{~V} \mathrm{~s}^{-1}$, to ensurethat all redox sites were accessed.

\section{Results and Discussion}

Ligand E lectrochemistry. The potentiodynamic oxidation of $\left[\mathrm{H}_{2}(3-\mathrm{MeOsaltMe})\right]$ in strong donor solvents (DMF and $\left(\mathrm{CH}_{3}\right)_{2} \mathrm{SO}$ ) shows only anodic features: two peaks at 0.91 and $1.12 \mathrm{~V}$ in DMF and at 0.86 and $1.10 \mathrm{~V}$ in $\left(\mathrm{CH}_{3}\right)_{2} \mathrm{SO}$ (Supporting I nformation, Figure $\mathrm{S} 1$ ). With increasing scan rate, a positive peak potential shift is observed, along with an increase in peak current. This behavior is typical of an irreversible charge-transfer process and is similar to the electrochemical behavior observed for other Schiff base ligands, particularly $\left[\mathrm{H}_{2}\right.$ (saltMe)].17

In $\mathrm{CH}_{3} \mathrm{CN}$, the electrochemical behavior changes dramatically and depends on the potential scan rate. For low scan rates $\left(<0.02 \mathrm{~V} \mathrm{~s}^{-1}\right)$, the cyclic voltammogram is similar to the one described for DMF, with two irrevers-

(16) Glidle, A.; Hillman, A. R.; Bruckenstein, S.J . Electroanal. Chem. 1991, 318, 411

(17) Santos, I.; Vilas-Boas, M.; Piedade, M. F. M.; Freire, C.; Duarte, M. T.; Castro, B. Polyhedron 2000, 19, 655. 

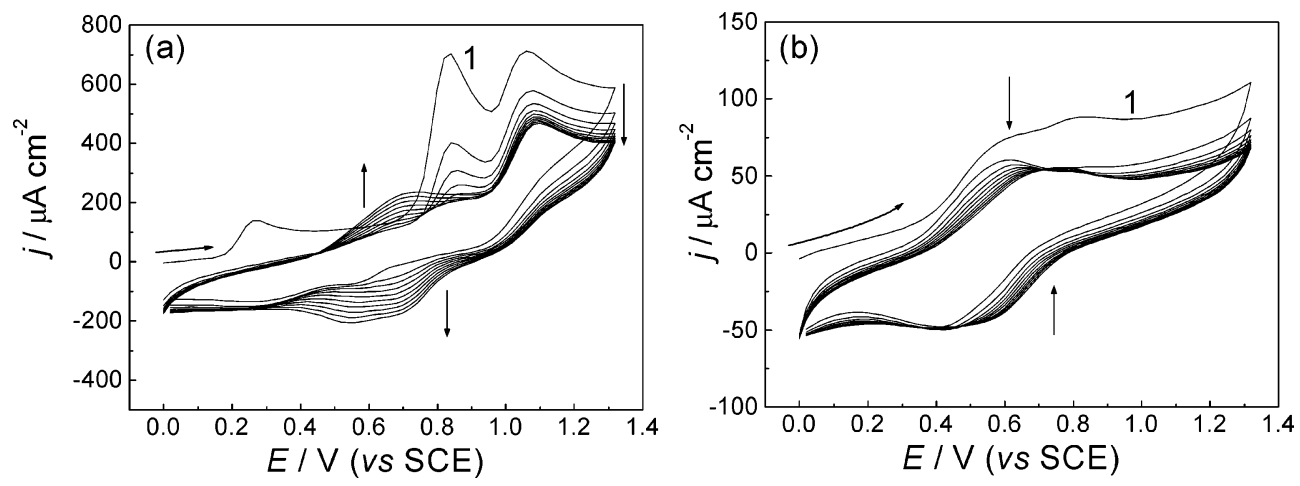

Figure 1. Series of sequential cyclic voltammograms of a Pt disk electrode between 0.0 and $1.3 \mathrm{~V}$ collected (a) in $1 \mathrm{mmol} \mathrm{dm}^{-3}$ $\left[\mathrm{H}_{2}\right.$ (3-MeOsaltMe)]/0.1 mol dm ${ }^{-3} \mathrm{TEAP} / \mathrm{CH}_{3} \mathrm{CN}$ at $1.0 \mathrm{~V} \mathrm{~s}^{-1}$ and (b) subsequently, for the same electrode, in monomer-free solution at $0.5 \mathrm{~V} \mathrm{~s}^{-1}$.

ible anodic waves. However, at higher scan rates, $v>$ $0.02 \mathrm{~V} \mathrm{~s}^{-1}$, the voltammogram becomes more complex, as illustrated in Figure 1a. During the first anodic cycle, we observethreefeatures, at $0.26,0.82$, and $1.03 \mathrm{~V}$. Thelatter two correspond to those observed in strong donor solvents. The first two features decrease markedly after the first cycle. Contrary to the results observed in DMF, the cathodic half-cycle also shows peaks at 0.55 and $0.70 \mathrm{~V}$, which increase in intensity with the number of potential cycles. On the second cycle, a new broad anodic wave appears at $0.72 \mathrm{~V}$ and follows the same pattern with respect to potential cycling as the corresponding cathodic features.

Overall, the observed behavior is characteristic of an irreversibleoxidation process, generating an el ectroactive deposit on the electrode surface. This was confirmed by direct visual observation of a yellow-greenish deposit and by the electroactivity shown for the modified el ectrode in monomer-free solution (seeF igure 1b). Although the film shows some activity at high scan rates, this modified electrode does not present sufficient electrochemical stability to warrant further studies.

Film Deposition. The oxidation of $\mathrm{Ni}(\mathrm{II}) \mathrm{N}_{2} \mathrm{O}_{2}$ Schiff base complexes derived from salicylaldehyde in strong donor solvents is known to yield reversible cyclic voltammograms associated with the formation of $\mathrm{Ni}(\mathrm{III})$ species stabilized through axial coordination of solvent molecules. ${ }^{17-20}$ However, oxidation of [Ni(3-MeOsaltMe)] in DMF and $\left(\mathrm{CH}_{3}\right)_{2} \mathrm{SO}$ resembles that observed in low donor solvents, in which the metal complex is irreversibly oxidized and there is deposition of a polymer film on the electrode surface; for $\left(\mathrm{CH}_{3}\right)_{2} \mathrm{SO}$ this is observed only at scan rate higher than $0.1 \mathrm{~V} \mathrm{~s}^{-1}$ (Supporting I nformation, Figure S2). ${ }^{1-4,6-8}$ Subsequently, when exposed to monomerfree solution, the modified electrodes do show electroactivity, but with limited stability in DMF, $\left(\mathrm{CH}_{3}\right)_{2} \mathrm{SO}$, and even $\mathrm{CH}_{3} \mathrm{CN}$. For this reason, we did not pursue studies of the modified electrodes prepared in strong donor solvents.

Oxidation of [Ni(salen)]-typemonomersin $\mathrm{CH}_{3} \mathrm{CN}$ leads totheformation of polymer films on the electrode surface. As previously observed, 7,8 the bulkiness of substituents in the ethylenimine bridge controls the stability and conductivity of thefilm. This effect must bepredominantly steric, not electronic, since the conduction path does not involve the imine bridge. 7,8

Oxidative polymerization of the new compound was monitored using the EQCM to see if ligand modification

(18) Freire, C.; Castro, B. Inorg. Chem. 1990, 29, 5113.

(19) Freire, C.; Castro, B.J . Chem. Soc., Dalton Trans. 1998, 9, 1491.

(20) Freire, C.; Castro, B. Polyhedron 1998, 17, 4227.
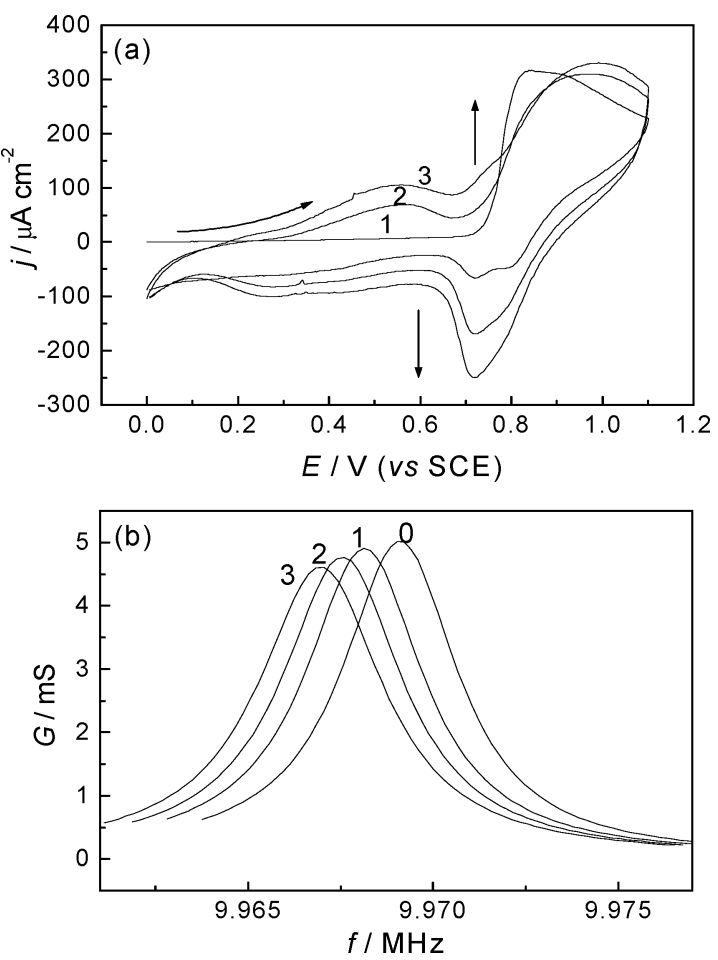

Figure 2. Series of sequential cyclicvoltammograms for anodic polymerization of $1 \mathrm{mmol} \mathrm{dm}^{-3}$ [Ni(3-MeOsaltMe)] in $0.1 \mathrm{~mol}$ $\mathrm{dm}^{-3} \mathrm{TEAP} / \mathrm{CH}_{3} \mathrm{CN}$ at a Pt/quartz-crystal electrode, between 0.0 and $1.1 \mathrm{~V}$ at $0.1 \mathrm{~V} \mathrm{~S}^{-1}$ (the positive potential limit was shortened from 1.3 to 1.1 V in order togain moreprecisecontrol over the amount of deposited material). (a) j versus E: (1) first, (2) second, and (3) third cycle. (b) G versus f spectra obtained at $0.0 \mathrm{~V}$ during the film deposition process: (0) bare el ectrode in $0.1 \mathrm{~mol} \mathrm{dm}^{-3} \mathrm{TEAP} / \mathrm{CH}_{3} \mathrm{CN}$ solution and after (1) the first, (2) the second, and (3) the third cycle.

(cf. [Ni(saltMe)]) resulted in mechanistic differences. Figure 2 shows representative vol tammetric and crystal admittance $(\mathrm{G})$ responses during the polymerization of [Ni(3-MeOsaltMe)] in $0.1 \mathrm{~mol} \mathrm{dm}{ }^{-3} \mathrm{TEAP} / \mathrm{CH}_{3} \mathrm{CN}$. We observe a sharp increase in current at $0.71 \mathrm{~V}$, followed by two incompletely resolved anodic waves (at 0.84 and $0.92 \mathrm{~V}$ ). On the reverse sweep, there are four peaks (at $0.80,0.72,0.43$, and $0.26 \mathrm{~V}$ ). The second anodic half-cycle shows two new broad anodic waves (at 0.26 and $0.56 \mathrm{~V}$ ), which correspond to oxidation of the film previously deposited on the previous anodichalf-cycle, that is, which are the anodic counterparts of the two low-potential reduction features. With theexception of theanodic waves observed on thefirst cycl e (which mergeto a broad feature at $1.0 \mathrm{~V}$ ), all the observed features show a continuous increase in peak current with the number of potential 

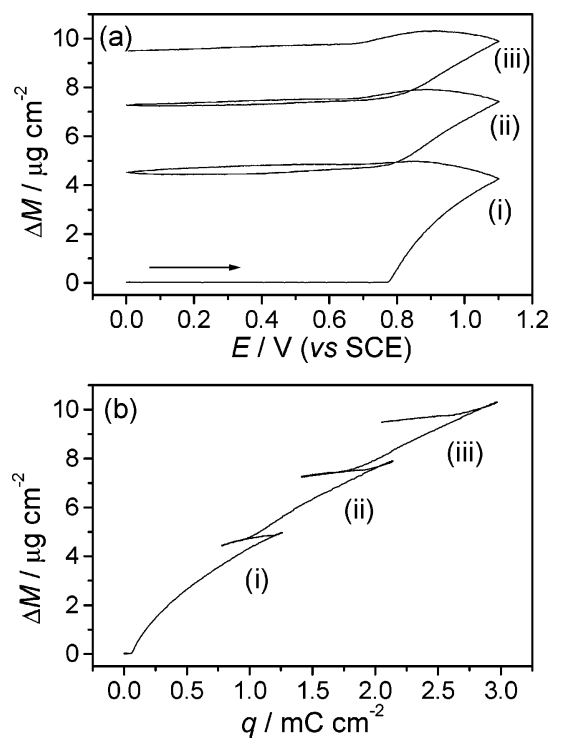

Figure 3. Gravimetric interpretation of the data of Figure 2, expressed as (a) $\Delta M$ versus $E$ and (b) $\Delta M$ versus q: (i) first, (ii) second, and (iii) third scan. Final film surface concentration $\Gamma=13 \mathrm{nmol} \mathrm{cm}-2$.

cycles asfar as was investigated (160 cycles). Theseresults, together with visual observation of a yellow-greenish film, all signal the presence of a polymeric material on the el ectrodesurface, as observed for similar complexes. ${ }^{1-4,6-8}$

Gravimetric interpretation of EQCM frequency responses involves application of the Sauerbrey equation, which applies strictly only if the attached film is rigidly coupled to the surface. ${ }^{21}$ Adherence to this criterion (or otherwise) can be determined on the basis of the crystal impedance spectrum. If the peak admittance is decreased by $10 \%$ or less by the presence of the film, deviation from theSauer brey equation is minimal; although it is possible to apply a correction term to account for these minor viscoelastic effects, 16,22 very little error is in practice incurred by ignoring them. On the basis of the data in Figure $2 \mathrm{~b}$, we conclude that films deposited using up to (morethan) threepolymerization cycles can beconsidered as acoustically thin (thick) and that a gravimetric (viscoelastic) interpretation is appropriate.

Although thecrystal impedance method provides much more information than the basic ("single point" resonant frequency) EQCM method, the latter has much greater time resolution. To obtain the benefits of both variants of thetechnique, weroutinely mademeasurementsin EQCM (resonant frequency measurement) mode throughout experiments, in conjunction with a determination of the full frequency response (admittance measurement) at the start and end of each experiment. In this way, we could unequivocally validate acoustically thin film characteristics and, where appropriate, apply a gravimetric interpretation (Sauerbrey equation) with completeconfidence. Thus, Figure 3 shows the gravimetrically interpreted EQCM response, as functions of potential and of charge passed, during the deposition of poly[Ni(3-MeOsaltMe)] at a Pt-coated quartz resonator. During the first potential scan, the electrodemass increases from $0.77 \mathrm{~V}$ in theanodic half-cycle until $0.85 \mathrm{~V}$ in the cathodic half-cycle and then there is a small decrease in mass until the end of the cycle: for the first cathodic half-cycle, $\Delta \mathrm{M}=5.0 \mu \mathrm{g} \mathrm{cm}^{-2}$ at $0.85 \mathrm{~V}$ and $4.5 \mu \mathrm{g} \mathrm{cm}^{-2}$ at $0.0 \mathrm{~V}$. On subsequent scans, although the film mass still increases significantly from

(21) Sauerbrey, G. Z. Phys. 1959, 155, 206.

(22) Ramirez, S.; Hillman, A. R.J . Electrochem. Soc. 1998, 145, 2640.
$0.77 \mathrm{~V}$, the process in fact commences at a lower potential, ca. $0.38 \mathrm{~V}$ : for the third cathodic half-cycle, $\Delta \mathrm{M}=$ $10.3 \mu \mathrm{g} \mathrm{cm}^{-2}$ at $0.85 \mathrm{~V}$ and $9.5 \mu \mathrm{gcm}^{-2}$ at $0.0 \mathrm{~V}$. Weattribute this latter effect to nucleation processes, as alsoindicated by the intercept on the charge axis of Figure 3b. Once these nucleation processes are completein the first cycle, and for all subsequent cycles, the mass-charge relationship is linear. This is consistent with a film of constant composition (i.e., thickness-independent ion and solvent content) that does not exhibit viscoelastic phenomena.

It is interesting to compare the above behavior with that previously observed for poly[Ni(saltMe)] films. ${ }^{5}$ The ratio of the slope of the linear segments in Figure $3 \mathrm{~b}$ to that predicted for a pure (solvent- and electrolyte-free) polymer film is 1.18; that is, the film is swelled by $18 \%$ (on a gravimetric basis) by the solution. For the unsubstituted [Ni(saltM e)] system, the corresponding ratiowas 1.15. ${ }^{5}$ The similarity in behavior between these two systems indicates that polymer formation is relatively insensitive to the el ectronic and steric changes associated with the methoxy substituent.

Film mor phol ogy was assessed using scanning el ectron microscopy; a representative image is shown in Figure S3a (Supporting Information). We find a continuous polymer layer, above which are irregular fragments. To confirm that the latter are part of the polymer surface, deposition experiments with the el ectrode cell immersed in an ultrasound bath weredone. FigureS3b,c (Supporting Information) illustrates thescanning electron micrographs of theresultant poly[Ni(3-MeOsaltM e)] films. Weareable to confirm the presence of the granular patches, and the peeling of one film clearly allows the observation of a compact morphology within the film interior, consistent with the low $(<20 \%)$ solvent content.

Redox Switching. Figure4a shows theelectrochemical behavior of a poly[Ni(3-MeOsaltMe)] film, after deposition, exposed to background electrolyte solution. It differs significantly from thosedescribed for other poly[ $\mathrm{Ni}$ (salen)]type polymers described in theliterature. During thefirst few (typically six) voltammetric cycles, the response evolves; thereafter it is reproducible. Werefer tothis initial cycling process as conditioning and, unless otherwise specified, report data for conditioned films. For such conditioned films, we observe four chemically reversible redox processes. Since the peak potential separation $(\Delta E)$ is small, we approximate the formal potential, $E^{\prime}$, as the average of the anodic and cathodic peak potentials: we find $E^{\prime}(I)=0.19 \mathrm{~V}, \mathrm{E}^{\prime}(\mathrm{II})=0.40 \mathrm{~V}, \mathrm{E}^{\prime}(\mathrm{III})=0.80 \mathrm{~V}$, and $\mathrm{E}^{\prime}(\mathrm{IV})=0.92 \mathrm{~V}$ (see Supporting I nformation, Table S1).

At low/moderate potential scan rates $\left(\mathrm{v}<0.2 \mathrm{~V} \mathrm{~s}^{-1}\right)$, voltammetric peak currents increased linearly with scan rate. This diffusionless behavior is consistent with complete redox conversion of the film. At higher scan rates $\left(v>0.2 \mathrm{~V} \mathrm{~s}^{-1}\right)$, thick films $\left(\Gamma>80 \mathrm{nmol} \mathrm{cm}{ }^{-2}\right)$ showed small deviations from this behavior. These responses can be summarized through the slopes of plots of log j versus $\log v$, which decrease from 1 (and which will ultimately reach 0.5; see Supporting Information, Figure S4), and the increase in $\Delta \mathrm{E}$. This transition reflects a changeover at shorter effectivetimescales (thicker films and/or faster scan rates) to rate control by coupled diffusion of el ectrons and counterions.

Chronoamperometric experiments were interpreted using the Cottrell equation ${ }^{7,23}$ toyiel d fil mchargetransport dynamics. Responses at intermediate times, uncomplicated by short time scale uncompensated resistance or long timescalefinitediffusion effects, provided the $D_{C A}{ }^{1 / 2} C$

(23) Paulse, C. D.; Pickup, P. G. J . Phys. Chem. 1988, 92, 7002. 


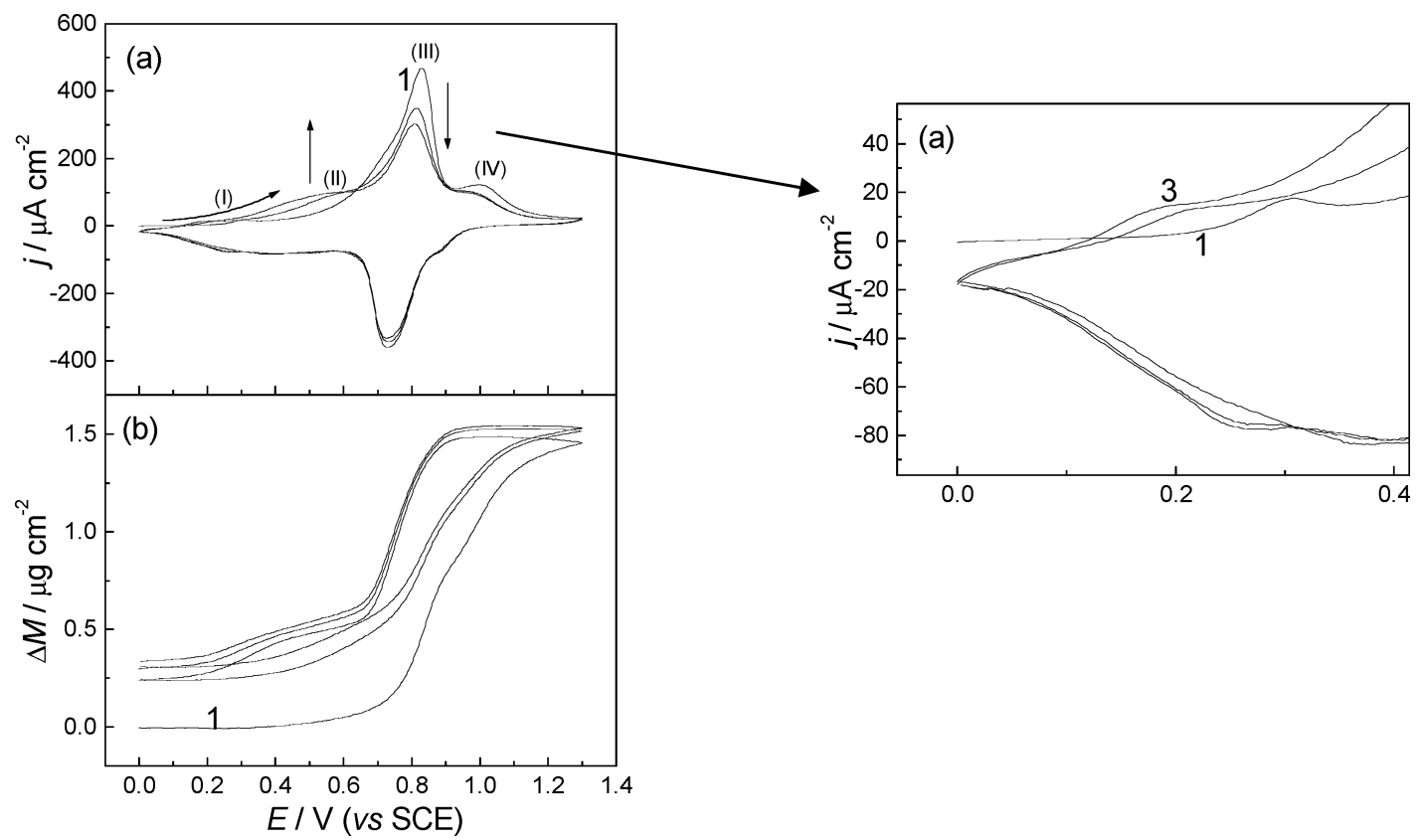

Figure 4. Responses to redox switching (first three cycles of a "rested" film) of the poly[Ni(3-MeOsaltMe)]-modified electrode in $0.1 \mathrm{~mol} \mathrm{dm}{ }^{-3} \mathrm{TEAP} / \mathrm{CH}_{3} \mathrm{CN}$, between 0.0 and $1.3 \mathrm{~V}$ at $0.1 \mathrm{~V} \mathrm{~s}^{-1}$, after deposition $\left(\Gamma=13 \mathrm{nmol} \mathrm{cm}^{-2}\right)$ : (a) j versus $\mathrm{E}$; (b) $\Delta \mathrm{M}(\mathrm{t})$ versus E. 1 and 3 denote cycle numbers; (I), (II), (III), and (IV) indicate the reversible redox processes observed. The arrowed right-hand box shows an expansion of the low-potential regime.

Table 1. Values of $D_{C A}{ }^{1 / 2} C$, Obtained from the Linear Part of the Chronoamperometric Response Using the Cottrell Equation, as a Function of Polymer Surface Concentration ${ }^{\mathrm{a}}$

\begin{tabular}{cccccc}
\hline \multirow{2}{*}{$\begin{array}{c}\text { number of } \\
\text { polymerization }\end{array}$} & \multirow{2}{*}{$\begin{array}{c}\Gamma / \\
\mathrm{nmol} \\
\text { cycles }\end{array}$} & \multicolumn{4}{c}{$10^{7} \mathrm{D}_{\mathrm{CA}} \mathrm{Cm}^{-2} \mathrm{C} / \mathrm{mol} \mathrm{cm}^{-2} \mathrm{~s}^{-1 / 2}$} \\
\cline { 3 - 6 } & $\begin{array}{c}0.0 \rightarrow 0.55 \\
\mathrm{~V}\end{array}$ & $\begin{array}{c}0.55 \rightarrow 0.0 \\
\mathrm{~V}\end{array}$ & $\begin{array}{c}0.0 \rightarrow 1.15 \\
\mathrm{~V}\end{array}$ & $\begin{array}{c}1.15 \rightarrow 0.0 \\
\mathrm{~V}\end{array}$ \\
\hline 3 & 20.5 & 0.03 & 0.64 & 0.05 & 2.09 \\
5 & 25.6 & 0.07 & 0.89 & 0.10 & 2.52 \\
10 & 37.1 & 0.27 & 0.75 & 1.45 & 2.78 \\
20 & 51.0 & 0.42 & 1.52 & 1.66 & 4.12 \\
30 & 70.1 & 0.56 & 1.55 & 2.56 & 4.37 \\
40 & 87.2 & 0.73 & 1.95 & 2.98 & 5.38 \\
50 & 106.0 & 0.88 & 2.14 & 3.38 & 5.83
\end{tabular}

a Note: entries relate to independently grown films.

data $\left(D_{C A}=\right.$ the effective charge transport diffusion coefficient; $\mathrm{C}=$ film electroactive site concentration) in Table 1. We find three primary trends in $D_{C A}{ }^{1 / 2} C$ : (i) an increase with $\Gamma$, (ii) lower values for anodic steps than the corresponding cathodicsteps, and (iii) smaller values over the potential interval $0.0 \rightarrow 0.55 \mathrm{~V}$ than for $0.0 \rightarrow 1.15 \mathrm{~V}$. Thesetrends can beexplained in terms of solvation effects, for which solvent population data will be produced below. Briefly, (i) thinner films are more compact, (ii) ion entry into reduced (less solvated) films is slower than ion expulsion from oxidized (solvated) films, and (iii) for a larger potential step, thelatter stages of oxidation involve ion transport through a partially oxi dized (thus, partially solvated) film.

The more complex polymer electrochemistry described here, as compared to that of other [ $\mathrm{Ni}$ (salen)]-type polymers, ${ }^{2,3,6-8}$ must arise from electronic effects associated with themethoxy substituent in theal dehydemoiety. I ndirectly this supports thespectroscopical ly derived idea that, as for other [ $\mathrm{Ni}(\mathrm{salen})]$-based systems studied, the redox process for poly[Ni(3-MeOsaltMe)] films must be ligand-centered, ${ }^{6,8}$ since a metal-centered redox process would be less sensitive to substituent effects. The full spectroscopic characterization (UV-Vis, FTIR, and EPR) will be published elsewhere.
Insight into theion transfer process(es) associated with film electron transfer is obtained through the EQCM gravimetric response shown in Figure 4b. As this figure shows, there is a significant "first scan" effect, in which there is additional uptake of mass (which we will show is largel y solvent) in thefirst anodic half-cycle. In repetitive cycling experiments (see Figure 4b), this solvent is "irreversibly" retained, but an extended "resting" period in the reduced state restores the initial, unsolvated form. Unless otherwise specified, data refer to a "conditioned" film after the initial cycle. Overall, the result is a mass increase (decrease) during theanodic (cathodic) half-cycle. Qualitatively, the implication is that incorporation of anions is the dominant mechanism by which electroneutrality is maintained; this will be quantified below. The irreversible component of the response to the first redox cycle is ca. $15 \%$ of the redox-driven mass changes (see Figure $4 b$ ), but only ca. $3 \%$ of the total film mass. This behavior is commonly observed for el ectroactivefilms. It is generally attributed to solvation changes in response to film structural changes that result in a change in "free volume" within the polymer. In the present context, the driver for the structural change is the need to align monomer units in a coplanar arrangement to maximize orbital overlap and thereby promotechargedel ocal ization along the polymer spine.

Superficial comparison of the electrochemical and gravimetric responses shown in Figure 4 indicates that they are not straightforwardly related. One should bear in mind that the differential format of thecurrent response is inherently more sensitive than the integral format of the mass response. Nevertheless, there are regions of potential in which charge flow appears to occur in the absence of mass transfer. This is a consequence of transfers of ions (here, anions) and solvent in opposite directions. The effect diminishes the observed net mass response-in the extreme, to zero. This compensatory motion phenomenon is commonly associated with a film volumeconstraint, a reasonable expectation for a rigid film.

Given that solvation changes occur, and indeed are significant, it is legitimate to ask whether they are 


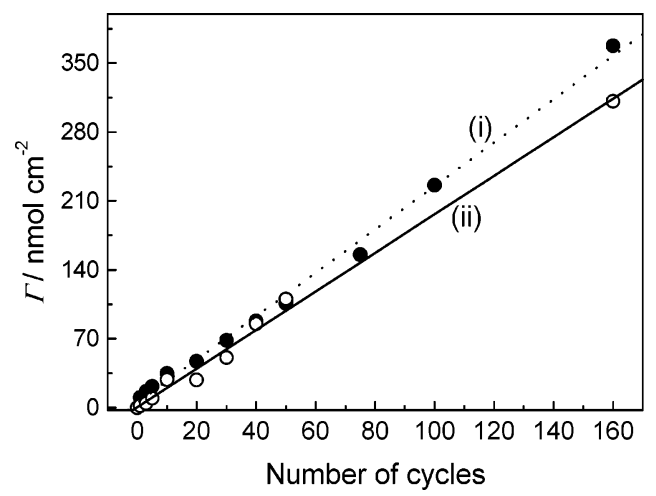

Figure 5. Plot of the surface el ectroactive surface concentration, $\Gamma$, with the number of potential cycles employed during film deposition: (i) (@) poly[Ni(3-MeOsaltMe)]; (ii) (O) poly[Ni(saltMe)].

sufficiently large as to plasticize the film, that is, make it viscoelastic. Measured resonant admittance values during and after the initial film oxidation changed by less than $1 \%$, validating the gravimetric interpretation of EQCM frequency responses. To quantify the population of film active sites on the basis of el ectrochemical data, it is necessary to know the number of electrons per monomer unit transferred in the redox process. This can be achieved in a double coulometric assay, ${ }^{6}$ in which one compares theanodiccharge passed in polymerization $\left(q_{p o l}\right)$ to the anodic charge passed in the subsequent redox switching $\left(q_{r e d}\right)$. In doing so, we note that polymerization per sein these poly[Ni(salen)]-based systems invol ves two electrons per monomer and is necessarily accompanied by film oxidation. Thus, $q_{\text {pol }} / q_{\text {red }}=(2+2 y+x) /(2 y+x){ }^{6}$ where $y$ and $x$ are the numbers of electrons transferred per phenyl and metal center, respectively. Assuming the same redox processes for poly[Ni(3-MeOsaltMe)] films, physically meaningful solutions (corresponding to an integer value of $\mathrm{x}$ ) for the above equation are only found for $x=0$; this corresponds to a ligand-based redox process. Using this value of $\mathrm{x}$, the experimental data yield $\mathrm{y}=$ $0.34 \pm 0.02$; this corresponds to polymer oxi dation by the injection of two positive charges delocalized over three monomer units (since there are two phenyl rings per monomer). This result is between those observed for poly[Ni(saltMe] $(y=0.5)^{8}$ and for poly[Ni(salen) $(y=0.12){ }^{6}$

An important practical outcomewith regard to catalytic applications is the facility to conduct charge, that is, the absence of a limitation imposed by charge transport. This is demonstrated (in Figure 5) by the linearity of electrochemically addressable sites with the number of polymerization cycles for as many as 160 cycles. This capability is correlated with theligand iminebridge. Similar behavior was seen for poly[Ni(saltMe)]. ${ }^{7}$ This contrasts with other [Ni(salen)]-type polymers we havestudied, namely, those with ethylenediamine, 1,1'-dimethyl-ethylenediamine, and cycl ohexanediamineimine bridges, for which apparent $\Gamma$ values achievea limiting value. ${ }^{10,24,25}$ I $n$ thelatter cases, access to film redox sites was limited at high surface concentration, a significant limitation for catalytic and other applications reliant upon rapid electron transport through the film.

Mobile Species Transfer. Full understanding of film redox switching requires information not only on el ectron transfer, but also on theassociated ion and solvent transfer

(24) Armengaud, C.; Moisy, P.; Bedioui, F.; Devynck, J .; BiedCharreton, C. J. Electroanal. Chem. 1990, 277, 197.

(25) Bedioui, F.; Merino, A.; Devynck,J .; Mestres, C.; Bied-Charreton, C. J . Electroanal. Chem. 1988, 239, 433.

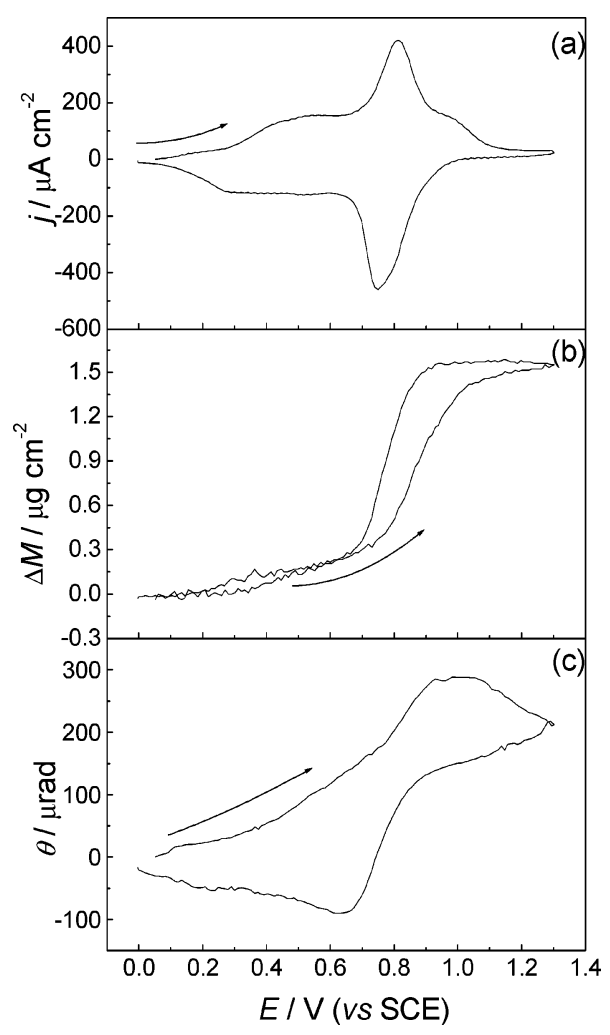

Figure 6. EQCM/PBD data for redox switching of a conditioned poly[Ni(3-MeOsaltMe)]-modified el ectrode, $\Gamma=13 \mathrm{nmol} \mathrm{cm}-2$ in $0.1 \mathrm{~mol} \mathrm{dm}-3 \mathrm{TEAP} / \mathrm{CH}_{3} \mathrm{CN}$, between 0.0 and $1.3 \mathrm{~V}$ at $0.1 \mathrm{~V}$ $\mathrm{s}^{-1}$ : (a) j, (b) $\Delta \mathrm{M}$, and (c) $\theta$ versus $\mathrm{E}$. Thelaser beam was located $103 \mu \mathrm{m}$ away from the electrode.

processes. To ascertain which mobile species are transferred during polymer redox switching (to satisfy electroneutrality and activity constraints), ${ }^{26,27}$ we performed a series of experiments using the EQCM/PBD technique. This is a combined electrochemical/gravimetric/optical method, the three responses to which (via the procedure of temporal convolution) provide the redox-driven population changes and fluxes of thethreemobilespecies present, that is, solvent, anion, and cation. $5,14,15,28,29$

Representative data are shown in Figure 6 for voltammetrically controlled redox switching of a poly[Ni(3MeOsaltMe)] film. The gravimetric $(\Delta \mathrm{M})$ and optical $(\theta)$ responses show a mass increase and a positive(away from the electrode) beam deflection as the film is oxidized, and the reverse during film reduction. Qualitatively, these features are consistent with anion incorporation (expulsion) as positive charges are introduced into (removed from) the polymer during film oxidation (reduction). We now proceed to quantify these responses.

The effective molar mass, $m$, for the species exchanged during the redox switching is defined as $\mathrm{ZF} \Delta \mathrm{M} / \mathrm{q}$, where $z$ is the ion valency, $F$ is the $F$ araday constant, and $\Delta M / q$ is the slope of the mass change versus charge plot shown in Figure 7. Data for the experiment of Figure 7 and analogues at other scan rates are summarized in Table 2. All plots showed two regions, with relatively little hysteresis (particularly in thelow-potential regime). Both regions of the plot showed reasonable linearity, with that

(26) Hillman, A. R.; Loveday, D. C.; Swann, M. J .; Bruckenstein, S.; Wilde, C. P. J . Chem. Soc., Faraday Trans. 1991, 87, 2047.

(27) Hillman, A. R.; Loveday, D. C.; Swann, M. J .; Bruckenstein, S : Wilde, C. P. Analyst 1992, 117, 1251.

(28) Vieil, E.; Lopez, C. J . Electroanal. Chem. 1999, 466, 218.

(29) Vieil, E.; Meerholz, K.; Matencio, T.; Heinze, J .J . Electroanal. Chem. 1994, 368, 183. 


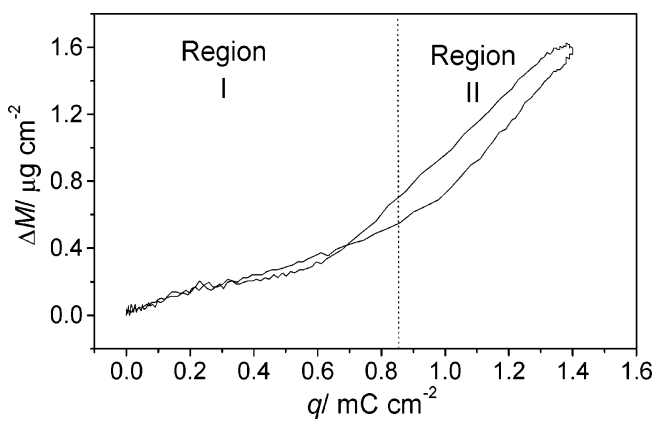

Figure 7. $\Delta M$ versus $\mathrm{q}$ profile obtained during the redox switching of the poly[Ni(3-MeOsaltMe)]-modified electrode of Figure 6: region I, $0.0-0.8 \mathrm{~V}$; region $\mathrm{II}, 0.8-1.3 \mathrm{~V}$.

Table 2. Values of the Effective Molar Mass, $m$, Obtained from the Slopes of the $\Delta M$ versus q Plots, for the Anodic Redox Switching of a Conditioned

Poly[Ni(3-MeOsaltMe)]-Modified Electrode at Different Scan Rates in $0.1 \mathrm{~mol} \mathrm{dm}^{-3} \mathrm{TEAP}^{-} \mathrm{CH}_{3} \mathrm{CN}$ $\left(\Gamma=13 \mathrm{nmol} \mathrm{cm}^{-2}\right)^{\mathrm{a}}$

\begin{tabular}{|c|c|c|c|c|c|}
\hline \multirow[b]{2}{*}{$v N \mathrm{~s}^{-1}$} & \multicolumn{2}{|c|}{$\mathrm{m} / \mathrm{g} \mathrm{mol}^{-1}$} & \multirow[b]{2}{*}{$v N \mathrm{~s}^{-1}$} & \multicolumn{2}{|c|}{$\mathrm{m} / \mathrm{g} \mathrm{mol}^{-1}$} \\
\hline & 1 & II & & I & II \\
\hline 0.5 & 66 & 261 & 0.05 & 78 & 155 \\
\hline 0.2 & 70 & 224 & 0.02 & 62 & 163 \\
\hline 0.1 & 73 & 176 & & & \\
\hline
\end{tabular}

a Region I, 0.0-0.8 V; region II, 0.8-1.3 V.

at lower potentials having the lower slope. Values of $m$ (Table 2) are not consistent, for either region or for any scan rate, with transfer of anion al one (which would yield $\mathrm{m}=99.5 \mathrm{~g} \mathrm{~mol}^{-1}$ for perchlorate). For $\mathrm{E}<0.9 \mathrm{~V}, \mathrm{~m}<99.5$ $\mathrm{g} \mathrm{mol}^{-1}$, al most independent of scan rate. This is consistent with anion transfer being the predominant process and, on average, ca. 0.7 solvent molecules leaving the film for every anion that enters. For $0.9<\mathrm{E} N<1.3, \mathrm{~m}>99.5 \mathrm{~g}$ $\mathrm{mol}^{-1}$, consistent with anion incorporation being accompanied by entry of solvent (and/or cation, as "salt"). The extent to which $m$ departs from the molar mass of perchlorate varies with potential scan rate. Taking the view that the film is permselective (see bel ow), the mass/ charge ratio indicates solvent transfer in the same direction as anion transfer and to the extent of 4 solvent molecules per anion, decreasing to 1.5 solvent molecules per anion as the scan rate is decreased. Interestingly, these solvation variations are in opposite directions and of rather different magnitudes for the two regions. Since the $\mathrm{m}$ value in region II tends toward the "simple" perchlorate result as the time scale increases (potential scan ratedecreases), this implies that thereareadditional transient processes (probably solvent-based) that eventually decay to zero.

Full interpretation of the data of Figure 6 and anal ogues at different scan rates requires correlation of all three responses. This is compl icated by the fact that thecurrent and mass responses relate directly to species fluxes detected at theel ectrode/solution interface, but theoptical responseis effectively "downstream" at somedistancefrom the interface. Diffusion of species to/from the interface is only detected optically at some later time, according to the distance of the probe beam from the surface (typically ca. $100 \mu \mathrm{m}$ ) and the relevant diffusion coefficients. This delay is handled using themathematical tool of convol ution anal ysis, 5,14,15,28-31 in which a diffusionally based transfer function is used to "project" the el ectrochemi cal (current,

(30) Csahok, E.; Vieil, E.; Inzelt, G.J . Electroanal. Chem. 1998, 457, 251.

(31) Vieil, E. J . Electroanal. Chem. 1994, 264, 9.

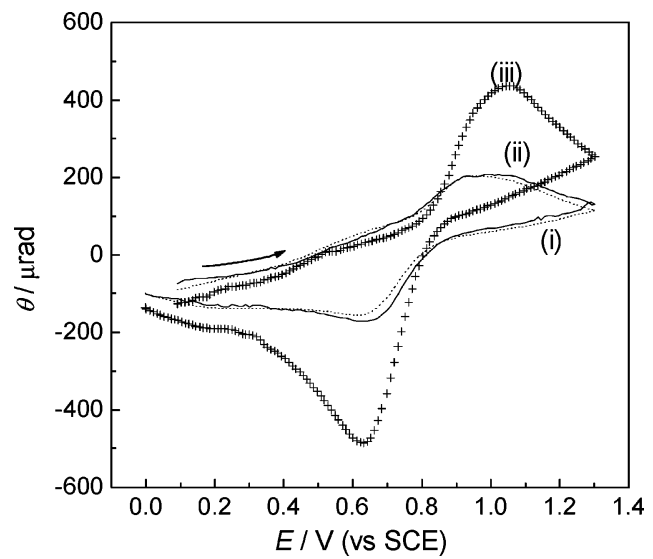

Figure 8. Comparison of $\theta$ (solid line), convolved current $\mathrm{j}(\mathrm{x}, \mathrm{t})$ (dotted line), and convolved mass variation $M(x, t)(+$ symbol s); data from Figure6. Convolution procedures werebased on $\mathrm{ClO}_{4}{ }_{-}^{-}$ as the only transferred species.

j) and gravi metric (expressed as a mass flux, $M$ ) responses a distance $x$ out into the solution where the optical $(\theta)$ response is obtained. In this way, the propagation delay caused by solution diffusion of mobile species between the electrode and the laser beam is effectively removed, allowing quantitative comparison of the electrochemical, gravimetric, and optical responses.

Details of the procedures for the convolution analysis are given elsewhere. $5,14,29$ In the present case, the optical response was modeled on the hypothesis that the pre dominant ion transferred is $\mathrm{ClO}_{4}^{-}$, so that any disparity between the optical and convolved current responses represents cation transfer.

Typical data for a conditioned film are shown in Figure 8. The immediate observation is that the experimental deflection profile is al most perfectly superimposed on the convolved current for the entire redox switching process. In contrast, the convol ved mass flux is very different from the optical response. The first of these observations suggests that perchlorate transfer is the dominant mechanism for maintaining electroneutrality, that is, cation transfer is minimal. The second observation signals significant transfer of solvent. In the latter case, there aretworegimes: in thelow-potential regimetheconvolved mass flux is bel ow theoptical response, indicating solvent expulsion, leading to values of $\mathrm{m}$ below the molar mass of perchlorate (see Table 2) and in the high-potential regime the reverse is true.

Using the methodology described previously, ${ }^{5}$ we can quantify these qualitative observations and extract the individual contributions (population changes and fluxes) of each species. Correlation of the optical and convolved current responses, neither of which responds tothesolvent component, yields the anion and cation contributions. Insertion of these values into the convolved mass flux then yields the solvent contribution.

The results from this mathematical analysis can be presented either as fluxes (the differential form, directly from Figure 8) or as population changes (the integrated form, $\Delta \Gamma / \mathrm{nmol} \mathrm{cm}^{-2}$ ). Herewefocus on thefilm population changes, shown in Figure 9, both for the initial cycle and after theattainment of steady state (here, thesixth cycle); the corresponding flux data are shown in the Supporting Information, FigureS5. Asthepoly[Ni(3-MeOsaltMe)] film is oxidized, el ectroneutrality is primarily maintained by the incorporation of $\mathrm{ClO}_{4}^{-}$; there is a small contribution by the expulsion of cations, which is slightly more marked for the first scan (Figure 9a) and at high scan rates. 


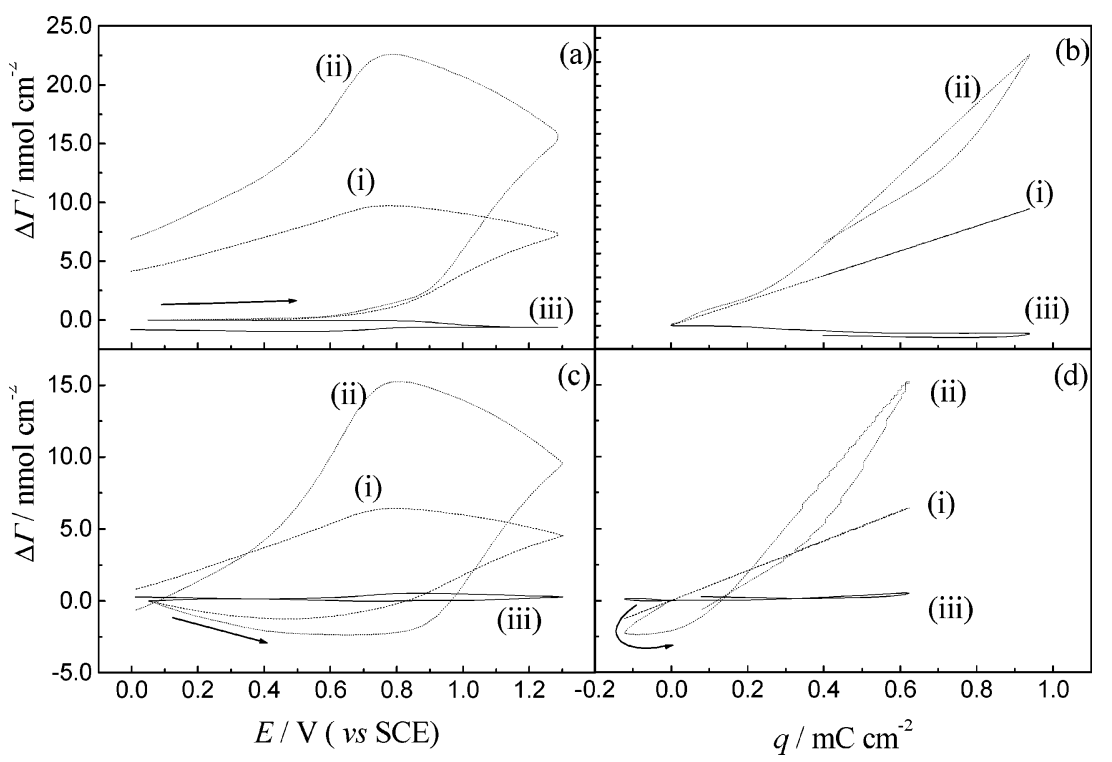

Figure 9. Film population changes, $\Delta \Gamma$, for (i) anion, (ii) solvent, and (iii) cation during (a,b) the first and (c,d) the sixth (steady state) redox cycle for the experiment of Figure $6 .(a, c) \Delta \Gamma$ vs potential; (b,d) $\Delta \Gamma$ vs charge density, obtained from the convolved current of the voltammogram.

This anion movement is foll lowed by theentry of solvent, as a result of either a concentration gradient or a physical opening of the polymer structureduring oxidation. At low potentials, theextent of solvent transfer is small: no more than $10 \%$ of the total population change. At higher potentials, solvent transfer is much more significant.

These effects are clearer when the population changes areplotted against the charge (seeFigure9b,d). Thenearabsence of cation participation necessarily generates a near-linear relationship between theanion population and thecharge (effectively, electron population); this is simply the result of Faraday's law and the electroneutrality condition. Themoreinformativeresult is therelationship between thesolvent population and thecharge. Comparing the traces marked (ii) in panels $b$ and $d$ of Figure 9, the main common feature is theincreasein solvent transferred per ion transferred (upturn in slope) after ca. 25\% oxidation. For the first scan, the presence of hysteresis only at the more oxidized end of the cycle suggests, al beit indirectly, that the solvent transferred at low charge density is associated with the ion, but that at least some of thesolvent transferred at higher chargedensity is "free" solvent that enters rather more slowly by a diffusive mechanism. The closer approach to linearity of the relationship between the solvent population and the charge(i.e., anion population) during film reduction shows that solvent expulsion is more facile than solvent entry. The difference between the solvent populations in panels b and $d$ of $F$ igure 9 is seen in the low chargedensity region; this is dueto theaccumulated kinetic "lag" of prior cycles, which is most pronounced where the kinetics is slowest, in solvent entry to a reduced film.

These results provide an explanation for chronoamperometry data, parametrized through the $C\left(D_{C A}\right)^{1 / 2}$ values in Table 1. In all cases, the effective chargetransport rate (broadly, the value of $\mathrm{D}_{\mathrm{CA}}$, since the $\mathrm{C}$ values are roughly constant) is smaller for oxidation than reduction. This is because oxidation of a reduced film requires anion entry into a relatively poorly solvated, that is, compact, film: this process is slow. Conversely, reduction of an oxidized (or partly oxidized) film requires anion expul sion from a relatively solvent swollen, that is, open, film: this process is relatively rapid. We note (see Table 1 ) that this trend is accentuated for thin films, which are generally more compact than thicker films.

One advantage to determining the individual species contributions to redox switching is that it is possible to identify the origin of changing responses with redox cycling. The initial cycle population profiles do not show closure: at the end of the cycle, the film retains some solvent and perchlorate (i.e., charge). On the other hand, the population profiles of a "conditioned" film do show closure at the end of the cycle. However, these latter population changes are necessarily smaller (compare panels a and c of Figure 9), since they only relate to the "reversible", that is, nontrapped, fraction of the ion and solvent population changes. Restoration of the initial, equilibrium film structure and composition can be facilitated by a "resting" period, during which the film is maintained in the reduced state.

\section{Conclusions}

[Ni(3-MeOsaltMe)] can be electrochemically polymerized from acetonitrile to give stable films. EQCM monitoring of coulometric and gravimetric responses during film deposition reveals an initial delay between charge passage and surface mass accumulation. This is characteristic of nucleation processes, in which sufficient reactant must be consumed to supersaturate the solution with product before the appearance of the new phase.

Substitution by the aldehyde moiety dramatically modifies polymer redox chemistry from that of the parent species: the voltammetric response has increased complexity and there is a shift between metal- and ligandbased redox chemistry. Comparison of thecharges involved in film polymerization and subsequent redox switching indicates that polymer redox chemistry involves transfer of 2e per 3 monomer units. Qualitatively, coulometric data for redox switching of thick films $\left(\Gamma \approx 350 \mathrm{nmol} \mathrm{cm}^{-2}\right)$ indicate facile film charge transport; these have been quantified in terms of $D_{C A}{ }^{1 / 2} C$ values from Cottrell plots. Thinner films $\left(\Gamma \approx 1-10 \mathrm{nmol} \mathrm{cm}^{-2}\right)$ areacoustically thin, allowing gravimetric interpretation of QCM responses. In combination with thePBD technique, this has provided determination of the individual contributions of anions, cations, and solvent to the overall redox process. 
Thefirst few redox cycles of a new film show progressive accumulation of anion and solvent. Thereafter the response attains a steady state, based upon transfers of anion (but negligiblecation) to mai ntain el ectroneutrality and of solvent. The overall redox process can be divided into two regions, from 0 to $0.8 \mathrm{~V}$ and from 0.8 to $1.3 \mathrm{~V}$. In region I, the mass/charge ratio is al most independent of scan rate; for every anion transferred, ca. 0.7 solvent molecules transfer in the opposite direction. In region II, the mass/charge ratio is dependent on scan rate. Solvent transfer is the predominant process (and is in the same direction as anion transfer) but decreases from 4 to 1.5 solvent molecules per anion as thescan rate is decreased. This implies that solvent entry is a transient process and that subsequent relaxation involves at least its partial expulsion. After a sequence of redox cycles, the initial "irreversible" behavior is restored by holding the film in a "resting" reduced state. I n summary, the solvent has a critical role, from determining at the outset whether a polymer film can bedeposited at all, through to controlling the subsequent dynamics of film charge transport.

Acknowledgment. We thank the British Council/ CRUP J oint Research Program (B-6/03), F undação para a Ciência e a Tecnologia, Lisboa (Project POCT/32831/ QUI/2000), and the EPSRC (GR/N 00968) for financial support.

Supporting Information Available: Details of convolution validation; cyclic voltammetry data for $\left[\mathrm{H}_{2}(3-\mathrm{MeO}-\right.$ saltMe)] and [ $\mathrm{Ni}(3-\mathrm{MeOsaltMe})]$; scanning el ectron micrographs of [Ni(3-MeOsaltMe)] film; dynamic studies of a poly[Ni(3MeOsaltMe)]-modified electrode; comparison of anion, cation, and solvent contributions to the flux; convolution parameter as a function of relative beam position. This material is available free of charge via the Internet at http://pubs.acs.org.

LA034525R 